\title{
Modern Parathyroid Surgery and Intra-Operative Hormone Monitoring; Present Status, Future Concepts \\ Shawky $\mathbf{M}^{1,2^{*}}$, Abdel-Aziz TE ${ }^{1,2}$, and Kurzawinski TR ${ }^{1}$ \\ ${ }^{1}$ Centre for Endocrine Surgery, University College London Hospital and Great Ormond Street Hospital, London, England, United Kingdom \\ ${ }^{2}$ Department of Head and Neck and Endocrine Surgery, Faculty of Medicine, University of Alexandria, Alexandria, Egypt
}

"Corresponding author: Shawky M, Centre for Endocrine Surgery, University College London Hospital and Great Ormond Street Hospital, London, England, United Kingdom, Tel: +44 203456 7890; E-mail: michael.s.shawky@gmail.com

Received date: December 22, 2017; Accepted date: January 20, 2018; Published date: January 25, 2018

Copyright: () 2018 Shawky M, et al. This is an open-access article distributed under the terms of the Creative Commons Attribution License, which permits unrestricted use, distribution, and reproduction in any medium, provided the original author and source are credited.

\begin{abstract}
New technologies look for practical applications and complex clinical problems search for innovations able to address them. This convergent course of clinical needs and technological innovation laid foundation for progress and success of modern health care. Our review looks at the present status and future concepts of parathyroid surgery in relation to important technological developments of the last few decades. We focus on describing how parathyroid operations have been transformed by the more accurate imaging and discuss impact of intra-operative PTH monitoring, a "disruptive technology" with a potential to change current clinical paradigm.
\end{abstract}

Keywords Hyperparathyroidism; Parathyroidectomy; Intraoperative parathyroid monitoring; Parathyroid hormone assay

\section{Introduction}

Primary Hyperparathyroidism (PHPT) is after diabetes and thyroid diseases the third commonest endocrine disorder and its incidence and prevalence is rising globally [1]. In the United Kingdom, the incidence of PHPT has been estimated to be $25 / 100,000$ and prevalence has risen from 1.8 to 6.7 per 1000 between 1997-2006 [2,3]. These staggering figures imply that in the UK alone about half a million people suffer from this condition and 12.000 develop it each year. Similar trend is observed worldwide with incidence as high as 195/100,000 reported among females aged 70-79 in Southern California [4]. Uncontrolled over-secretion of parathyroid hormone (PTH) and high levels of calcium in blood and urine, pathognomonic features of PHPT cause significant morbidity and decrease quality of life. Some of the consequences of PHPT such as renal stones, osteoporotic fractures, and pancreatitis have been known for a century and became classical indications for parathyroidectomy. Association between PHPT and hypertension, cerebrovascular and cardiovascular events, diabetes, cancer and increased mortality have recently been recognized and widened criteria for surgery in patients previously classified as asymptomatic [5-7]. Not surprisingly, number of Para thyroidectomies performed in the NHS hospitals has doubled between 2000 and 2010 with similar trend is observed in other countries [8,9]. At the same time NHS in the UK and health systems in other countries are under severe financial pressure and reducing the cost of providing healthcare while maintaining excellent outcomes is their priority.

Introduction of intra-operative PTH monitoring concept based on defining biochemical cure by detecting $50 \%$ reduction of PTH concentration within minutes after removal of abnormal gland ushered in a new possibility of changing old paradigms by promise of improving overall cure rate reducing number of preoperative scans while increasing number of minimally invasive procedures. We performed a structured search of Medline and Embase Data base using Ovid interface with keywords extracted from the relevant $\mathrm{MeSH}$ headings which were then combined giving the following search terms: (intraoperative and parathyroid), (quick assay and parathyroid) and (point-of-care and parathyroid). We included only human studies in English. Our review focuses on status of intra-operative PTH (IOPTH) monitoring in modern parathyroid surgery and discusses biological principle it is based on. It explores challenges of IOPTH monitoring and the need for future developments to enable its full potential as a 'disruptive technology' and facilitate its wide spread adoption.

\section{Current Clinical Paradigm: The Dominant Role of Pre- operative Imaging}

Historically, parathyroid surgery based on a principle of bilateral neck exploration (BNE), exposure of all four glands and removal of abnormal parathyroids as judged by their size has been performed for almost a century with remarkable success [10]. It relied on surgeon's experience in interpreting intra-operative findings rather than on preoperative imaging and this led to popular view that "the only thing you need to localize before parathyroid surgery is a good surgeon". However, majority of patients with sporadic PHPT have only one abnormal gland, while multiple glands involvement is less common $(10 \%-15 \%)$ [1]. Therefore, surgical excision of the single overactive gland is curative in $85 \%-90 \%$ of cases and routine practice of full neck exploration with direct visualization of all glands was gradually replaced by Minimally Invasive Para thyroidectomy (MIP) as the new standard in most patients with sporadic PHPT [11-13]. MIP also known as focused parathyroidectomy is performed through small incisions and aims at removing just one gland. Successful implementation of MIP required accurate preoperative localization of the abnormal glands, and the current era of MIP is therefore heavily reliant on preoperative imaging modalities known as localization studies $[14,15]$. The two most popular tests used in current practice are neck ultrasound where criteria for defining abnormal gland is its size and nuclear scan MIBI where the strength of isotope signal corresponds to mitochondrial activity/density which enable identification of abnormal gland. Ultrasound is inexpensive widely available and has long been used to localize abnormal parathyroids 
with a reported sensitivity ranging from $27 \%-89 \%[16,17]$. However US is known to be operator dependent, not useful for retro-sternal mediastinal lesions and less sensitive for small sized and hyperplastic parathyroids especially when associated with thyroid nodules [18]. MIBI scan has been used to supplement sonographic localization with a reported sensitivity of $58 \%-90 \%[19,20]$ but its sensitivity is compromised with lower preoperative PTH level, multi-gland pathology and intake of $\mathrm{Ca}$ channel blockers [21,22]. Inability to confidently localize parathyroid adenoma with only one type of scan has led to the practice of performing both scans in an attempt to increase their accuracy. Concordant US and MIBI results signify precise co-localization by both imaging modalities and have been shown to localize solitary parathyroid adenoma with $95 \%$ sensitivity [23]. This level of certainty has generally been accepted as sufficient and patients with concordant findings are considered good candidates for MIP. The problem is that scans are concordant in only $65 \%$ of cases while discordant, negative or equivocal results which represent lack of co-localization have been frequently reported respectively in $38 \%$, $17 \%$, and $8 \%$ of cases $[24,25]$. Surgeons are hardwired for success but averse to failure and to maximize their chances of curing patients with single operation they pursue positive concordant localization allowing them to perform MIP.

Patients with discordant imaging often undergo further repetitive US and MIBI scans or have CT, MRI, choline or methionine nuclear scans, angiography or selective venous sampling (SVS) at a cost of increased radiation exposure, expense and patients inconvenience $[26,27]$. In cases when results of multiple scans remain inconclusive patients are scheduled for full neck exploration when "key hole" approach would be sufficient and bear negative implications such as unnecessary bigger scars, slower recovery and longer hospital stay, and sometimes are even advised against the operation.

\section{Intra-Operative PTH Monitoring: Current Status}

\section{Evolution of PTH assay}

Parathyroids play a central role in regulating calcium homeostasis by synthesis of new PTH, and its release from secretory granules. Changes in the concentration of calcium are sensed by calcium sensing receptors on chief cells and their adjusted activity results in rapid alterations in PTH secretion. PTH is an 84-amino acid peptide that binds to PTH receptor one and by activating adenylyl cyclase modulates bone metabolism, synthesis of 1,25-dihydroxyvitamin D in proximal tubules and reabsorption of calcium in the distal nephron. $\mathrm{N}$ terminal end of PTH is the domain involved in receptor activation and intact (1-34) region mimics the biological actions of the whole (1-84) peptide [28]. Assays recognizing $\mathrm{N}$ truncated PTH fragments are in fact measuring biologically inactive PTH fraction, an issue of concern in patients with renal impairment in whom $\mathrm{C}$ terminal fragments accumulate significantly [29]. The first generation PTH assay described by Berson in 1963 was a competitive immunoassay employing single radio-labeled antibodies directed either against $\mathrm{N}$ terminal, mid molecule or $\mathrm{C}$ terminal regions of the PTH peptide [30-33]. Its accuracy was limited because of their cross reaction with biologically inactive PTH fragments. In 1987, Nussbaum has introduced second generation of non-competitive immunoassays, which employed "sandwich technique" where two antibodies are directed against different regions of the PTH peptide [34]. A radio- or luminescencelabeled detector antibody is usually directed against the $\mathrm{N}$ terminal region of the PTH peptide (1-34) and a capture antibody is attached to a solid phase and directed against the $\mathrm{C}$ terminal region of the PTH peptide [35]. Despite the improved accuracy of the latter assays they still cross react with non-bio active amino-truncated PTH fragment (7-84) mainly because the low specificity of the amino targeted antibodies. Third generation immune-assays have consequently been developed with a higher specificity of the N-terminal directed antibody i.e. recognizing only the first four to six $\mathrm{N}$-terminal amino acids [36] thereby detecting at least theoretically only bioactive (1-84) PTH.

\section{Principles behind Intra-Operative PTH Monitoring}

These developments increased accuracy of PTH assays but they remained confined to the main hospital laboratory and used exclusively for routine diagnostics where long time to result (hours) was not a disadvantage. Timing of the assay became relevant when concept of observing dynamic changes of PTH concentration during parathyroid surgery and using this information to determine whether removal of abnormal parathyroid cured patient of hyperparathyroidism was introduced in 1988 by Nussbaum. He established that dropping PTH concentration to less than $40 \%$ of the baseline after 15 minutes of parathyroidectomy correlated with operative success (Figure 1) [37].

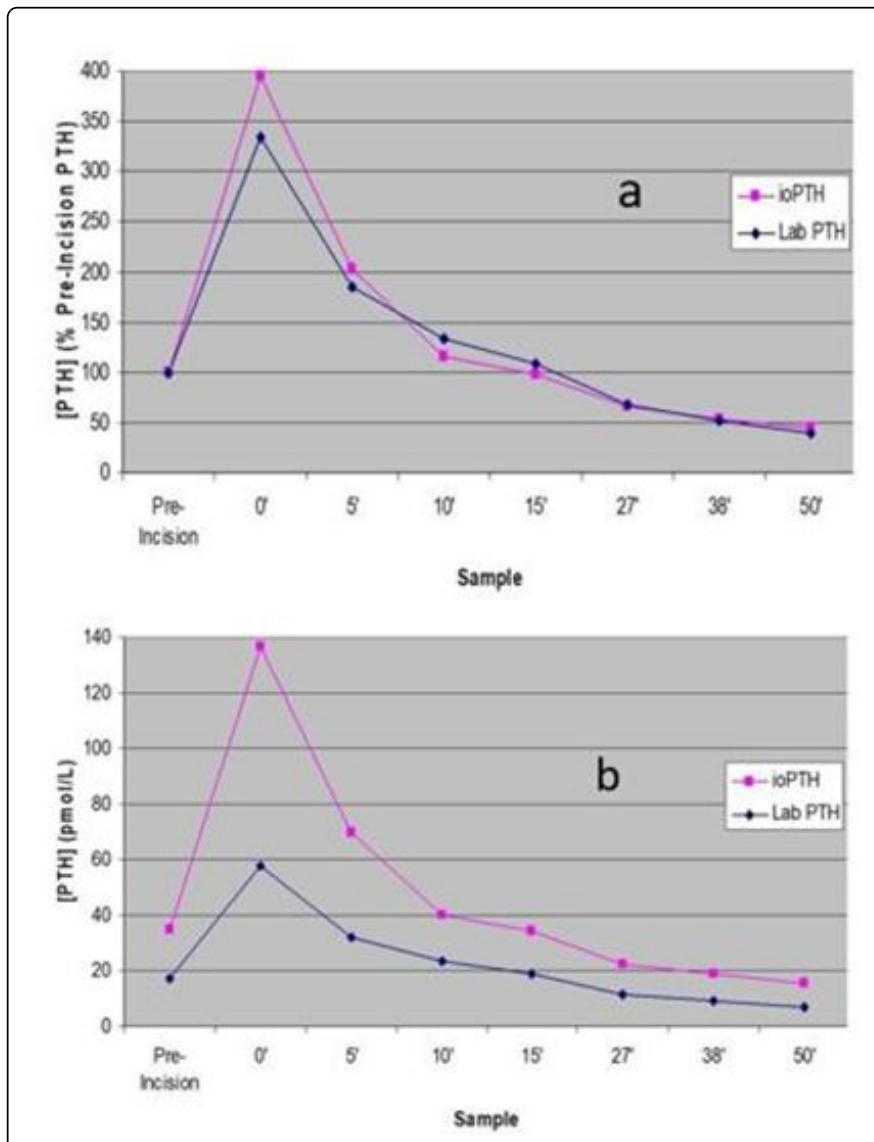

Figure 1: Dynamic changes of intra-operative PTH concentration measured in theatre on POC device (IOPTH) and main hospital platform (Lab PTH) expressed as (a) percentage of pre-incision value and (b) absolute values.

This strategy was based on three physiological facts: firstly PTH short half-life (mean $3 \mathrm{~min}, 28 \mathrm{sec}$ ); secondly being exclusively secreted 
Page 3 of 10

from the chief cells of the parathyroid gland; and thirdly suppression of the normally functioning glands by the excess of PTH [38,39]. Intraoperative PTH monitoring was further championed by Irvin who in 1993 proposed and evaluated a criterion for prediction of cure subsequently known as "Miami" criterion [40]. Other criteria for biochemical cure were subsequently developed taking into account three factors; baseline PTH concentration measured either before incision or after gland dissection just before its removal, concentration of PTH 5, 10 or 15 minutes after resection, and either $50 \%$ reduction in PTH concentration or its return to normal values. Main differences between these criteria are the point of reference of initial and final PTH concentration and its timing (Table 1).

\begin{tabular}{|c|c|c|c|c|c|c|c|c|c|}
\hline Drop & Baseline & Time & & Sensitivity & Specificity & PPV & NPV & Accuracy & Ref \\
\hline \multicolumn{10}{|l|}{ By percentage } \\
\hline$\geq 50 \%$ & Highest & 5 & & $88-91.7$ & $97-100$ & $99-100$ & $64-80$ & $90-93.8$ & {$[41,84]$} \\
\hline$\geq 50 \%$ & Highest & 10 & Miami & $97-97.8$ & $54.3-93.3$ & $99-99.6$ & $70-88$ & $92.9-97.3$ & {$[41,45,49]$} \\
\hline$\geq 50 \%$ & Pre-incision & 10 & Vienna & $82.1-92.2$ & 88.6-99 & $96.8-99.6$ & $56-60.9$ & $80-92.3$ & {$[41,45,49,85]$} \\
\hline$\geq 50 \%$ & Pre-excision & 10 & & $78-85$ & 97 & 100 & 58 & $78-87$ & {$[41,86]$} \\
\hline$\geq 50 \%$ & Pre-incision & 15 & Wisconsin & 100 & 100 & 100 & 100 & 100 & [78] \\
\hline$\geq 50 \%$ & Highest & 20 & & 96.5 & 93.3 & 99.4 & 70 & 96.3 & [87] \\
\hline \multicolumn{10}{|l|}{ To an absolute value } \\
\hline$\geq 50 \%$ AND normal & Highest & 10 & Mayo & $75-96$ & $86-98$ & 99 & $42-68$ & $79-95$ & {$[41,75]$} \\
\hline$\geq 50 \%$ AND normal & Pre-incision & 10 & & 91.8 & 66.7 & 98.7 & 22.2 & 90.9 & [77] \\
\hline$\geq 50 \%$ AND below pre-incision value & Highest & 10 & & $94-100$ & $93-97$ & $97-99$ & $77-100$ & $95-98$ & {$[41,55]$} \\
\hline Low normal $\leq 35 \mathrm{pg} / \mathrm{ml}$ & None & 15 & Halle & $62.9-69.8$ & $88.6-100$ & $98-100$ & $14.2-27.2$ & $65-71.9$ & {$[45,49]$} \\
\hline $50 \%$ And/Or normal & Highest & 20 & Rome & $82.9-83.2$ & $90-100$ & $99.4-100$ & $21.4-26.3$ & $83.6-83.8$ & {$[45,88]$} \\
\hline \multicolumn{10}{|l|}{ Analysis of drop kinetics } \\
\hline \multicolumn{4}{|c|}{ Formula for generation of PTH decay curve } & 100 & 80 & 96.7 & 100 & 97 & [89] \\
\hline \multicolumn{4}{|l|}{ Regression based nomogram } & 95 & 53.8 & 97.2 & 38.9 & 92.8 & [90] \\
\hline
\end{tabular}

Table 1: Reliability (performance) of IOPTH monitoring using different criteria for cure.

\section{Potential Errors and their Prevention}

A false positive result is encountered when after the removal of enlarged parathyroid, PTH concentration drops to level indicating cure but the patient remains hypercalcaemic. This has been observed more frequently in patients with parathyroid cancer, double adenoma, concomitant thyroid surgery and renal impairment [41-44]. Technical errors resulting in underestimating PTH concentration could also lead to false positive results [41]. A false negative result on the other hand is defined as persistence of elevated PTH after the removal of suspicious gland and further exploration shows no additional parathyroid pathology and in due course the patient becomes normocalcaemic. False negative results are more likely if stringent criteria for cure i.e. those requiring drop to normal range (example: Halle and Rome) are used [45]. Excessive manipulation of the adenoma may induce a preexcision spike resulting in post excision IOPTH not falling adequately despite eradication of the causative pathology $[46,47]$. Employing a pre-incision baseline based protocol (example: Vienna) in these cases would therefore increase the risk of false negative results [48].

Good understanding of physiology and dynamics of PTH curves in different diseases and willingness to apply this knowledge in interpreting PTH levels are the best way to avoid these pitfalls. Employing protocols using "strictly defined" rather than the "highest attained" baseline and requiring drop to "normal" would avoid false positive results and work better in patients with multi-gland disease $[41,49]$. Patients with well localized adenomas would be best served by protocols requiring only $50 \%$ IOPTH drop since, they have the highest accuracy in this scenario [45]. Excessive manipulation of the adenoma results in a pre-excision spike and early devascularisation during the dissection leads to premature decrease of the PTH concentrations, recognizing these pre-excision peaks and troughs, their correct interpretation as well as avoiding undue manipulation of the gland prior to its excision, and collecting the pre-excision sample while the gland is still on an intact vascular pedicle should respectively avoid false negative and false positive results [47,50].

Another potential source of error could be due to the lack of understanding that different platforms use various antibodies and PTH concentrations will vary by about $10 \%-15 \%$. This applies to measurements on different laboratory platforms as well as comparison between main laboratory and Point of Care (POC) devices used in the same hospital [35]. Proper calibration of the assay with strict adherence to manufacturer instructions preferably one day before the planned surgery to give time for technical support if needed, is essential to avoid technical errors. 


\section{Performance Consistency of IOPTH in Different Clinical Scenarios}

Patients diagnosed with PHPT and undergoing parathyroidectomy could significantly differ in age, vitamin $\mathrm{D}$ status, and renal function and have several other co morbidities which potentially could affect accuracy of IOPTH testing. Their hyperparathyroidism could also differ in severity be either sporadic or familiar and caused by abnormality of single or multiple glands. Current evidence in the published literature summarised in Table 2 suggests that intraoperative PTH monitoring performs consistently and accurately in those different clinical scenarios and can be used in all patients with PHPT (Table 2).

\begin{tabular}{|c|c|c|c|c|}
\hline Patient & $\mathbf{N}$ & Subgroups & performance & Ref \\
\hline Age & 833 & $<47,47-73$ or $>73$ years & $\begin{array}{l}\text { Sensitivity, PPV and accuracy of IOPTH were not statistically different among patients aged } \\
<47,47-73 \text { and }>73 \text { years, and were consistently high. (Ranges: } 93-97 \%, 96-99 \% \text { and } \\
90-96 \%)\end{array}$ & [91] \\
\hline $\begin{array}{l}\text { Vitamin } \quad \text { D } \\
\text { status }\end{array}$ & 351 & sufficient or deficient & $\begin{array}{l}\text { Sensitivity and accuracy of IOPTH were not statistically different between vitamin D } \\
\text { sufficient and deficient patients. }\end{array}$ & {$[92,93]$} \\
\hline $\begin{array}{l}\text { Renal function } \\
\text { Disease }\end{array}$ & 950 & NRF or CRI & $\begin{array}{l}\text { Percentage of true positive IOPTH results was not statistically different between NRF and } \\
\text { CRI patients ( } 95 \% \text { and } 97 \% \text { at } 15 \text { minutes, is respectively) }\end{array}$ & {$[94]$} \\
\hline Severity & 707 & Mild or conventional & $\begin{array}{l}\text { accuracy of IOPTH was consistently high among patients with mild or conventional PHPT } \\
(95 \% \text { and } 98 \% \text { respectively) }\end{array}$ & [95] \\
\hline $\begin{array}{l}\text { Number of } \\
\text { diseased } \\
\text { glands }\end{array}$ & 222 & SGD or MGD & $\begin{array}{l}\text { Sensitivity and accuracy of IOPTH were } 95 \% \text { and } 72 \% \text { in SGD and MGD respectively, and } \\
\text { were considerably higher than US and MIBI }\end{array}$ & {$[60]$} \\
\hline Gland weight & 59 & $\begin{array}{l}\text { Small }(<1 \mathrm{~g}) \text {, large }(1-3 \mathrm{~g}) \\
\text { giant }(>3 \mathrm{~g})\end{array}$ & $\begin{array}{l}\text { Sensitivity and accuracy of IOPTH were not statistically different among patients with small, } \\
\text { large or giant tumours (Overall Sensitivity and accuracy } 94.8 \% \text { and } 93.2 \% \text { respectively) }\end{array}$ & [92] \\
\hline \multirow{3}{*}{$\begin{array}{l}\text { Type of the } \\
\text { disease }\end{array}$} & 51 & Sporadic & $\begin{array}{l}\text { Sensitivity, specificity, PPV, NPV and accuracy of IOPTH was 98, 100, 100, 94, 98\% } \\
\text { respectively }\end{array}$ & [96] \\
\hline & 52 & Familial (MEN) & $\begin{array}{l}\text { Sensitivity, specificity, PPV, NPV and accuracy of IOPTH was } 93.5,0,0,87.8 \text { respectively, } \\
\text { with } \geq 75 \% \text { drop as the cure criterion. }\end{array}$ & [97] \\
\hline & 24 & Familial isolated & $\begin{array}{l}\text { Sensitivity, specificity, PPV, NPV and accuracy of IOPTH was } 100,71,89,100,92 \% \\
\text { respectively- IOPTH performed considerably better than US and MIBI }\end{array}$ & [98] \\
\hline
\end{tabular}

Table 2: Performance of IOPTH in different patient and disease (PHPT) scenarios.

\section{Advantages of Using IOPTH Monitoring}

When IOPTH monitoring during parathyroid surgery was first introduced to clinical practice 30 years ago the greatest expected benefits were improvement of cure rates preventing surgical failures and avoidance of re-operations. It has been enthusiastically adopted by some surgeons advocating its use but scorned by others who claimed that cure rates were already high and introducing this technology was unnecessary. Recently, surgical approach to parathyroidectomy has shifted from full neck exploration to minimally invasive approach with the latter becoming a definite gold standard for majority of patients with PHPT [12]. This has added more weight to the argument in favor of using IOPTH to increase number of 'key hole' procedures without compromising high cure rate. Using IOPTH when MIP is planned has been recently recommended by American Association of Endocrine Surgeons [51]. Additionally, using IOPTH has a potential to reduce number of pre-operative scans with subsequent cost savings.

\section{Improvement of surgical cure rates}

The unique advantage of IOPTH monitoring is that it provides accurate and real-time information about concentration of PTH and guides surgical decision whether removal of a parathyroid gland was curative, and procedure can be stopped, or further exploration should be carried on. The ability to predict cure during the operation is an exclusive feature of this technology not shared with other intraoperative adjuncts such as frozen section biopsy or methylene blue which are now made obsolete. Early reports compared results of BNE without and MIP with IOPTH and showed that MIP with IOPTH not only maintained high cure rate of BNE but also improved it by $1 \%-3 \%$. Majority of more recent publications comparing MIP with and without IOPTH in patients with concordant or discordant imaging have shown improved cure rate by $3 \%-15 \%$ when IOPTH was performed. Studies including only patients with concordant US and MIBI demonstrated smaller gain from IOPTH improving cure rate by $1 \%-5.5 \%$ only two studies showed cure rate to be the same, or paradoxically worse possibly related to simultaneous use of radioactive guidance and small number of patients in the study [52,53]. Impact of IOPTH on re operative surgery is not well documented with one study showing no improvement and one demonstrating $18 \%$ improved cure rate with IOPTH use (Tables 3-5) [54,55].

\begin{tabular}{|l|l|l|l|l|l|}
\hline \multicolumn{2}{|l|}{ BNE- No IOPTH } & \multicolumn{2}{l|}{ MIP-IOPTH } & S? & R \\
\hline N & CR\% & N & CR\% & & \\
\hline 340 & 94 & 421 & 97 & S & {$[99]$} \\
\hline 401 & 97 & 255 & 99 & NS & {$[71]$} \\
\hline 55 & 89 & 49 & 90 & NR & {$[100]$} \\
\hline 62 & 98 & 14 & 100 & NS & {$[101]$} \\
\hline
\end{tabular}


Page 5 of 10

\begin{tabular}{|l|l|l|l|l|l|}
\hline 184 & 97.3 & 33 & 100 & NS & {$[102]$} \\
\hline 44 & 97.7 & 47 & 95.7 & NR & {$[103]$} \\
\hline
\end{tabular}

Table 3: Cure rate in patients undergoing BNE without IOPTH and MIP with IOPTH.

\begin{tabular}{|c|c|c|c|c|c|}
\hline \multicolumn{2}{|c|}{ No IOPTH } & \multicolumn{2}{|c|}{ IOPTH } & \multirow[t]{2}{*}{ s? } & \multirow[t]{2}{*}{$\mathbf{R}$} \\
\hline $\mathbf{N}$ & CR\% & $\mathbf{N}$ & CR\% & & \\
\hline 40 & 85 & 13 & 100 & $S$ & [104] \\
\hline 87 & 93.1 & 80 & 97.5 & NR & [73] \\
\hline 15 & 100 & 5 & 100 & ND & [52] \\
\hline 62 & 91.9 & 115 & 99.1 & $S$ & [79] \\
\hline 157 & 90 & 188 & 100 & $S$ & {$[78]$} \\
\hline 39 & 94.1 & 14 & 100 & NS & [105] \\
\hline 44 & 97.7 & 47 & 95.7 & NS & [53] \\
\hline
\end{tabular}

Table 4: Cure rates in patients undergoing MIP without IOPTH vs. MIP with IOPTH.

\begin{tabular}{|l|l|l|l|l|}
\hline $\mathbf{N}$ & $\mathbf{C R} \%$ & IOPTH added & $\mathbf{S} ?$ & $\mathbf{R}$ \\
\hline 322 & 99 & $1 \%$ & NS & {$[57]$} \\
\hline 127 & 100 & $5.5 \%$ & NR & {$[106]$} \\
\hline 260 & 99.6 & $3.1 \%$ & S & {$[45]$} \\
\hline 338 & $97.9 \%$ & $4.1 \%$ & S & {$[107]$} \\
\hline
\end{tabular}

S: significant, NS: not significant, NR: not reported, ND: not different, CR: cure rate

Table 5: Cure rate in patients with concordant imaging undergoing parathyroidectomy with IOPTH.

\section{Increased Frequency of MIPs}

Benefits of MIP are widely accepted by patients, surgeons and health providers and include less pain, quicker recovery, better cosmetic results and shorter hospital stay. There is a clear advantage in offering this approach to as many patients with PHPT as possible but current practice is based on performing it only in patients with concordant findings on US and MIBI.

MIP has been traditionally contraindicated in cases with discordant or equivocal imaging results because up to $14 \%$ of these patients have multiple gland involvement [56,57]. However, the ability of IOPTH monitoring to predict cure during surgery with high accuracy has encouraged many surgeons to perform MIP in patients who do not have perfect co-localization of abnormal parathyroid on imaging.

Published evidence in Table 6 shows that MIP was possible in 63\% to $86 \%$ of patients with non-concordant imaging, with high cure rate of $93 \%-98 \%$, which suggests that IOPTH monitoring has a potential to increase overall number of patients being selected and successfully treated with MIP and that using this technology should increase surgeons' confidence in achieving high cure rate (Table 6).

\begin{tabular}{|l|l|l|l|l|l|l|}
\hline \multirow{2}{*}{ N } & \multicolumn{2}{|l|}{ Cured } & \multicolumn{3}{|l|}{ MIP } & R \\
\cline { 2 - 7 } & N & $\%$ & Attempted & Completed & $\%$ & \\
\hline 50 & 49 & $98 \%$ & 50 & 43 & 86 & {$[87]$} \\
\hline 201 & 195 & $97 \%$ & 201 & NR & NR & {$[57]$} \\
\hline 85 & 79 & $93 \%$ & 85 & 56 & 66 & {$[24]$} \\
\hline 143 & 138 & $97 \%$ & 143 & 114 & 80 & {$[108]$} \\
\hline 106 & NR & NR & NR & 80 & 66.6 & {$[25]$} \\
\hline 67 & 66 & 98.5 & 67 & 42 & 62.7 & {$[109]$} \\
\hline
\end{tabular}

Table 6: Cure rate in patients with discordant or equivocal imaging undergoing parathyroidectomy with IOPTH.

\section{Reduction in Number of Pre-Operative Imaging and Adoption of the "Single Scan" Paradigm}

Perhaps the most exciting potential of intra-operative PTH monitoring in becoming "disruptive technology" could be its ability to change current paradigm which heavily relies on concordant multiple scans, and replacing it with a pragmatic step wise use of pre-operative imaging.

Currently used imaging modalities have similar ability to identify abnormal parathyroid and are more accurate when parathyroid are larger, heavier and inferiorly located but less so in patients with greater BMI, milder HPT, multiple glands pathology and nodular thyroid disease [58-60]. Comparison of US and MIBI in 120 patients showed no statistically significant difference in accuracy or positive predictive value (74\% vs. $82 \%$ and $93 \%$ vs. $90 \%$, respectively) [61].

Limited yield of second scan is demonstrated in two studies of 97 and 226 patients where US localized abnormal parathyroid in 84 (sensitivity $87 \%$ ) and 173 (sensitivity $77 \%$ ) cases while MIBI additionally localized only 6 and 30 cases $[62,63]$.

These data suggest that multiple imaging aiming at concordant localization is not necessary and could be replaced by new paradigm which would rely on identification of abnormal parathyroid by single scan. The choice of the scan will depend on local radiological expertise but US should be considered as the first choice of investigation and additional scan such as CT or MIBI would be indicated only when initial imaging is negative.

Positive localization of a single abnormal gland cannot guarantee that its removal will achieve cure and surgeons would be reluctant to base their decision on this information alone. IOPTH monitoring however, has unique ability to predict cure and its superior performance in comparison to imaging both in initial and re-operative parathyroid surgery is demonstrated by studies summarized in Table 7. This shift of the burden of proof of predicting cure from pre-operative planning to intra-operative decision making is possible because biochemical monitoring is better than imaging at informing surgeons how many parathyroid glands need to be removed.

Other perioperative adjuncts commonly used in parathyroid surgery can't give such guidance. Frozen section and methylene blue can confirm that removed tissue is parathyroid but cannot reliably differentiate between adenoma and hyperplasia and says nothing about 
Page 6 of 10

function of remaining parathyroids and therefore don't improve cure rate [64-67].

IOPTH appears to perform better than gamma probe and one prospective study on 254 PHPT patients reported higher sensitivity, PPV and accuracy of IOPTH compared to radio-guided surgery $(99 \%$, $100 \%$ and $98 \%$ vs. $93 \%, 89 \%$ and $83 \%$, respectively) [68].
IOPTH monitoring is therefore the only technology capable of real time functional confirmation of cure with high sensitivity, specificity and accuracy. It promises to re-establish the continuum of reasoning based on biochemical criteria by bridging the gap between diagnosis of PHPT and definition of cure both defined in biochemical terms (Table 7).

\begin{tabular}{|c|c|c|c|c|c|c|}
\hline Patients & $\mathbf{N}$ & Investigation & Sensitivity & PPV & Accuracy & Ref \\
\hline \multirow[b]{3}{*}{ Patients who underwent initial surgery for benign PHPT } & \multirow[b]{3}{*}{1361} & US & $61 \%$ & $93 \%$ & $56 \%$ & \multirow[b]{3}{*}{ [110] } \\
\hline & & MIBI & $86 \%$ & $87 \%$ & $81 \%$ & \\
\hline & & IOPTH & $98 \%$ & $99 \%$ & $98 \%$ & \\
\hline \multirow[b]{3}{*}{ Patients who underwent re-operative surgery for benign PHPT } & \multirow[b]{3}{*}{228} & US & $68 \%$ & $82 \%$ & $61 \%$ & \multirow[b]{3}{*}{ [111] } \\
\hline & & MIBI & $81 \%$ & $90 \%$ & $77 \%$ & \\
\hline & & IOPTH & $99 \%$ & $98 \%$ & $97 \%$ & \\
\hline \multirow[b]{3}{*}{ Patients who were operated for PHPT } & \multirow[b]{3}{*}{350} & US & $76.1 \%$ & $75.0 \%$ & $60.7 \%$ & \multirow[b]{3}{*}{ [112] } \\
\hline & & MIBI & $71.6 \%$ & $76.7 \%$ & $59 \%$ & \\
\hline & & IOPTH & 99.3 & 98.3 & 97.8 & \\
\hline \multirow[b]{3}{*}{ Patients who were operated for sporadic PHPT } & \multirow[b]{3}{*}{143} & US & 84.6 & 100 & 84.6 & \multirow[b]{3}{*}{ [113] } \\
\hline & & MIBI & 95 & 98.5 & 93.7 & \\
\hline & & IOPTH & 97.8 & 99.3 & 97.2 & \\
\hline \multirow[b]{3}{*}{ Patients who were operated for sporadic PHPT } & \multirow[b]{3}{*}{57} & US & 61.5 & 96.0 & 61.5 & \multirow[b]{3}{*}{ [114] } \\
\hline & & $\mathrm{MIBI}$ & 93.0 & 96.4 & 93.0 & \\
\hline & & IOPTH & 98.1 & 100 & 98.1 & \\
\hline
\end{tabular}

Table 7: Results of studies comparing the performance of IOPTH, US and MIBI.

\section{Intra-Operative PTH Monitoring: Future Concepts}

IOPTH monitoring despite its significant advantages has not been universally adopted by surgeons performing parathyroid surgery. In the final paragraph of this review we identify and analyze possible barriers preventing this technology from wider adoption and discuss solutions able to get round them.

\section{Main Laboratory vs. Point of Care PTH Testing}

Logistics of current IOPTH monitoring is perhaps the most significant barrier to the adoption of this technology. Endocrine surgeons wishing to perform intra-operative PTH monitoring have a choice of either using their main laboratory or investing in Point-ofCare (POC) system which will allow PTH to be measured in the operating theatre. Routine diagnostic techniques used in main laboratories are not well suited for this particular testing need as they require not only complex infrastructure and skilled workforce but also willing cooperation of laboratory staff to accept inconvenience of dealing with samples arriving from operating theatre at unpredictable times. Main laboratories are stretched by providing routine diagnostic services and it is difficult for them to arrange for the ad hoc measurements of PTH on the main platform or release staff to attend operating sessions. This can interfere with their routine work and could be a critical barrier limiting its adoption.
The only currently available alternative solution is POC IOPTH system (example: Future Diagnostics) which is designed to be used in operating theatre as it is based on the large trolley equipped with multiple devices used during the assay, a valuable resource in operating theatre. Despite being superior to using main laboratory; it is bulky and occupies space; and importantly it still requires trained laboratory personnel and understaffed hospitals laboratories are reluctant to release them for off-site duties. This limits the ability of surgeons to schedule parathyroid operations when required and might have an impact on waiting times for parathyroid surgery.

Recent advances in engineering and bio-chemistry opened a possibility of constructing POC diagnostic devices which are simpler to operate and can be used by nurses or doctors already in theatre without a need for a dedicated laboratory technician. Innovation is needed in designing such a device for intraoperative PTH monitoring whose reliability of guiding the treatment in real time must reflect laboratory accuracy but at the same time allow measurements to be done anywhere and anytime without presence of the technician [69]. Such a device would have transformative effect on care of patients with PHPT [70]. 


\section{Time to Result}

Length of parathyroid surgery depends on multiple factors including not only the time needed to find abnormal single or multiple parathyroid which usually depends on the experience of the surgeon performing surgery but also choice of operating technique and perioperative adjuncts.

Published studies have demonstrated significantly shorter operative times in IOPTH-guided MIPs in comparison to BNEs without IOPTH $[71,72]$ a finding almost certainly related to extent of dissection; being less in MIP. However, when MIP is performed addition of IOPTH can make operating time longer [52,73]. Such extra time is attributed to sample transportation which could be significantly longer if main laboratory is used but negligible if POC device is based in the operating theatre. Specimen preparation on all currently available platforms requires centrifugation of EDTA blood sample and takes minimum 3 minutes; this is followed by a sequel of time consuming steps such as pipetting, incubation and washout before readout could be obtained $[35,74]$. Speed of assay readout is very important as PTH is measured 4 to 5 times five minutes apart and currently each measurement takes 10-18 minutes or longer (example: STAT IO-IPTH, FD and Elecsys 2010, RD). Clearly, new generation of POC microfluidic devices based in theatre and able to provide results in 3 to 5 minutes will be a great advantage. Relying on the drop of PTH concentration at 5 minutes will reduce number of measurements and time of surgery. Richards et al have shown that a $50 \%$ reduction has been observed in the five-minute measurement in $73 \%$ of cases making further testing in these patients unnecessary [75].

\section{Cost}

Use of the intra-operative PTH monitoring in its current format increases costs of parathyroidectomy incurred in the operating theatre and two cost analysis studies concluded that additional expense might not be justified because of only modest increase in cure rate and risk of false results [76,77]. However, both reports have restricted their case scenarios to patients with well localized abnormal parathyroid in which IOPTH is known to contribute least and neither of them considered the cost savings from increased number of MIPs, shorter hospital stay, and potential saving on preoperative imaging.

Cost savings associated with reduced hospitalization have been well documented in series where MIP with IOPTH was compared with BNE [71,72] and MIP without PTH monitoring [78,79]. IOPTH guided MIP performed as day-case with subsequent cost-effectiveness has been also shown to be safe and successful procedures in patients with well localized single gland parathyroid disease [80].

Pooling of more PHPT patients in a dedicated parathyroid surgery list would reduce the cost. Unpublished data from our institution showed IOPTH and FS come at a cost of $£ 1845$ and $£ 1705$, when five patients are operated on a single day as per our current practice $(£ 369$ and $£ 341$ per patient respectively). IOPTH cost comes from the use of two IOPTH test kits (48 tests each) $£ 920$, pay for laboratory staff $£ 500$, equipment $£ 215$, service contract $£ 185$, EQA $£ 15$, and incidentals $£ 10$. Further calculations showed the two IOPTH kits currently used for 5 patients can provide adequate measurements for seven patients reducing costs further and making IOPTH cheaper than FS ( $£ 264$ per patient) [81]. Costs of calibration, price of assays and laboratory support could be potentially significantly reduced by new technical innovations leading to development of microfluidic POC devices [82].
Adoption of the aforementioned "single scan paradigm" would also significantly reduce the cost. Recent study on 208 PHPT patients operated at our institution showed that US correctly localized the disease in 193 out of 208 patients. In the remaining 15 patients MIBI was correct in 3 , incorrect in 8 , and negative in 4 patients. Importantly, in all 15 patients IOPTH was correct in predicting cure in 6 (true positive) or prompting further exploration in 9 (true negative) patients. Costs were calculated in two hypothetical scenarios using the new tariffs (US $£ 100$, MIBI $£ 1000$, and IOPTH $£ 400$ ). Using all three modalities, we have cured 203 out of 208 patients at a cost of $£ 1500$ per patient. Using classic combination of US and MIBI would have cured 196 out of 208 patients at a cost of $£ 1100$ per patient but combination of US and IOPTH would have cured 202 out of 208 patients at a cost

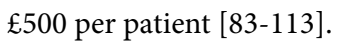

\section{Summary}

Diagnosis and criteria for cure of the PHPT are biochemical and it is anachronism that during the operation surgeon has to rely on surrogate information such as size, weight or histopathology of parathyroid glands. IOPTH has potential to re-establish biochemical continuum in pre, intra and post-operative reasoning.

Intra-operative PTH monitoring accurately defines cure in whole spectrum of patients with sporadic and familiar PHPT regardless of their age, renal function, vitamin $\mathrm{D}$ status, weight and number of affected glands. It consistently outperforms pre-operative imaging tests in predicting cure and by doing so shows potential to reduce reliance on multiple scans, radiation exposure, patient's inconvenience and overall costs and increase number of minimally invasive procedures while maintaining high cure rate.

Current methods used to monitor PTH concentration are to slow, expensive and logistically difficult. Development of novel "Lab on a chip" ultrafast, cheap and simple devices which can perform all steps automatically without need from human interference, will reduce time, cost, improve logistics, and un-clatter operating theatre, and by doing so place surgeon at the center of decision making by giving him access to vital information in real time and encourage wider utilization of this beneficial technology.

\section{Acknowledgement}

M.S.S. would like to thank the Ministry of Higher EducationMissions sector, Egypt and the British Council for their support through Newton-Musharafa programme via the Egyptian Cultural Bureau in London.

\section{References}

1. Madkhali T, Alhefdhi A, Chen H, Elfenbein D (2016) Primary hyperparathyroidism. Ulus Cerrahi Derg 32: 58-66.

2. Ozbas S, Pain S, Tang T, Wishart GC (2003) Surgical management of primary hyperparathyroidism- Results of a national survey. Ann R Coll Surg Engl 85: 236-241.

3. Yu N, Donnan PT, Murphy MJ, Leese GP (2009) Epidemiology of primary hyperparathyroidism in Tayside, Scotland, UK. Clin Endocrinol 71: 485-493.

4. Yeh MW, Ituarte PH, Zhou HC, Nishimoto S, Liu IL, et al. (2013) Incidence and prevalence of primary hyperparathyroidism in a racially mixed population. J Clin Endocrinol Metab 98: 1122-1129.

5. Yu N, Donnan PT, Leese GP (2011) A record linkage study of outcomes in patients with mild primary hyperparathyroidism: The parathyroid 
epidemiology and audit research study (PEARS). Clin Endocrinol 75 169-176.

6. Goswami S, Ghosh S (2012) Hyperparathyroidism: Cancer and mortality. Indian J Endocrinol Metab 16: S217-220.

7. Bilezikian JP, Brandi ML, Eastell R, Silverberg SJ, Udelsman R, et al. (2014) Guidelines for the management of asymptomatic primary hyperparathyroidism: Summary statement from the Fourth International Workshop. J Clin Endocrinol Metab 99: 3561-3569.

8. Sackett WR, Barraclough B, Reeve TS, Delbridge LW (2002) Worldwide trends in the surgical treatment of primary hyperparathyroidism in the era of minimally invasive parathyroidectomy. Arch Surg 137: 1055-1059.

9. Griebeler ML, Kearns AE, Ryu E, Hathcock MA, Melton LJ, et al. (2015) Secular trends in the incidence of primary hyperparathyroidism over five decades (1965-2010). Bone 73: 1-7.

10. Chen H (2002) Surgery for primary hyperparathyroidism: What is the Best approach. Ann Surg 236: 552-553.

11. Moalem J, Guerrero M, Kebebew E (2009) Bilateral neck exploration in primary hyperparathyroidism-when is it selected and how is it performed. World J Surg 33: 2282-2291.

12. Reilly DJ, Chew GL, Eckhaus J, Smoll NR, Farrell SG (2016) Outcomes for minimally invasive parathyroidectomy: Widening inclusion criteria based on preoperative imaging results. ANZ J Surg 86: 701-705.

13. Laird AM, Libutti SK (2016) Minimally invasive parathyroidectomy versus bilateral neck exploration for primary hyperparathyroidism. Surg Oncol Clin N Am 25: 103-118.

14. Mohebati A, Shaha AR (2012) Imaging techniques in parathyroid surgery for primary hyperparathyroidism. Am J Otolaryngol 33: 457-468.

15. Kunstman JW, Kirsch JD, Mahajan A, Udelsman R (2013) Clinical review: Parathyroid localization and implications for clinical management. J Clin Endocrinol Metab 98: 902-912.

16. De Feo ML, Colagrande S, Biagini C, Tonarelli A, Bisi G, et al. (2000) Parathyroid glands: Combination of (99m)Tc MIBI scintigraphy and US for demonstration of parathyroid glands and nodules. Radiology 214: 393-402.

17. Gilat H, Cohen M, Feinmesser R, Benzion J, Shvero J, et al. (2005) Minimally invasive procedure for resection of a parathyroid adenoma: The role of preoperative high-resolution ultrasonography. J Clin Ultrasound 33: 283-287.

18. Johnson NA, Tublin ME, Ogilvie JB (2007) Parathyroid imaging: Technique and role in the preoperative evaluation of primary hyperparathyroidism. Am J Roentgenol 188: 1706-1715.

19. Tublin ME, Pryma DA, Yim JH, Ogilvie JB, Mountz JM, et al. (2009) Localization of parathyroid adenomas by sonography and technetium tc 99m sestamibi single-photon emission computed tomography before minimally invasive parathyroidectomy: Are both studies really needed. J Ultrasound Med 28: 183-190.

20. Saengsuda Y (2012) The accuracy of 99m Tc-MIBI scintigraphy for preoperative parathyroid localization in primary and secondary-tertiary hyperparathyroidism. J Med Assoc Thai 95: S81-91.

21. Kannan S, Milas M, Neumann D, Parikh RT, Siperstein A, et al. (2014) Parathyroid nuclear scan. A focused review on the technical and biological factors affecting its outcome. Clin Cases Miner Bone Metab 11: 25-30.

22. Khorasani N, Mohammadi A (2014) Effective factors on the sensitivity of preoperative sestamibi scanning for primary hyperparathyroidism. Int J Clin Exp Med 7: 2639-2644.

23. Patel CN, Salahudeen HM, Lansdown M, Scarsbrook AF (2010) Clinical utility of ultrasound and $99 \mathrm{mTc}$ sestamibi SPECT/CT for preoperative localization of parathyroid adenoma in patients with primary hyperparathyroidism. Clin Radiol 65: 278-287.

24. Lew JI, Solorzano CC, Montano RE, Carneiro-Pla DM, Irvin GL (2008) Role of intraoperative parathormone monitoring during parathyroidectomy in patients with discordant localization studies. Surgery 144: 299-306.
25. Khan AA, Khatun Y, Walker A, Jimeno J, Hubbard JG (2015) Role of intraoperative $\mathrm{PTH}$ monitoring and surgical approach in primary hyperparathyroidism. Ann Med Surg 4: 301-305.

26. Kluijfhout WP, Pasternak JD, Drake FT, Beninato T, Gosnell JE, et al. (2016) Use of PET tracers for parathyroid localization: A systematic review and meta-analysis. Langenbecks Arch Surg 401: 925-935.

27. Hader C, Uder M, Loose RW, Linnemann U, Bertsch T, et al. (2016) Selective venous blood sampling for hyperparathyroidism with unclear localization of the parathyroid gland. Rofo 188: 1144-1150.

28. Janulis M, Wong M, Favus MJ (1993) Structure-function requirements of parathyroid hormone for stimulation of 1, 25-dihydroxyvitamin D3 production by rat renal proximal tubules. Endocrinology 133: 713-719.

29. Brossard JH, Lepage R, Cardinal H, Roy L, Rousseau L, et al. (2000) Influence of glomerular filtration rate on non-(1-84) parathyroid hormone (PTH) detected by intact PTH assays. Clin Chem 46: 697-703.

30. Berson SA, Yalow RS, Aurbach GD, Potts JT (1963) Immunoassay of bovine and human parathyroid hormone. Proc Natl Acad Sci USA 49: 613-617.

31. Desplan C, Jullienne A, Moukhtar MS, Milhaud G (1977) Sensitive assay for biologically active fragment of human parathyroid hormone. Lancet 2 : 198-199.

32. Marx SJ, Sharp ME, Krudy A, Rosenblatt M, Mallette LE (1981) Radioimmunoassay for the middle region of human parathyroid hormone: Studies with a radioiodinated synthetic peptide. J Clin Endocrinol Metab 53: 76-84.

33. Simon M, Cuan J (1980) C-terminal parathyrin (parathyroid hormone) radioimmunoassay in serum with commercially available reagents. Clin Chem 26: 1666-1671.

34. Nussbaum SR, Zahradnik RJ, Lavigne JR, Brennan GL, Nozawa-Ung K, et al. (1987) Highly sensitive two-site immunoradiometric assay of parathyrin, and its clinical utility in evaluating patients with hypercalcemia. Clin Chem 33: 1364-1367.

35. Sokoll LJ, Wians FH, Remaley AT (2004) Rapid intraoperative immunoassay of parathyroid hormone and other hormones: A new paradigm for point-of-care testing. Clin Chem 50: 1126-1135.

36. Gao P, Scheibel S, D'Amour P, John MR, Rao SD, et al. (2001) Development of a novel immunoradiometric assay exclusively for biologically active whole parathyroid hormone 1-84: Implications for improvement of accurate assessment of parathyroid function. J Bone Miner Res 16: 605-614.

37. Nussbaum SR, Thompson AR, Hutcheson KA, Gaz RD, Wang CA (1988) Intraoperative measurement of parathyroid hormone in the surgical management of hyperparathyroidism. Surgery 104: 1121-1127.

38. Leiker AJ, Yen TW, Eastwood DC, Doffek KM, Szabo A, et al. (2013) Factors that influence parathyroid hormone half-life: Determining if new intraoperative criteria are needed. JAMA Surg 148: 602-606.

39. Chia SH, Weisman RA, Tieu D, Kelly C, Dillmann WH, et al. (2006) Prospective study of perioperative factors predicting hypocalcemia after thyroid and parathyroid surgery. Arch Otolaryngol Head Neck Surg 132: 41-45.

40. Irvin GL, Dembrow VD, Prudhomme DL (1993) Clinical usefulness of an intraoperative "quick parathyroid hormone" assay. Surgery 114: 1019-1022.

41. Carneiro DM, Solorzano CC, Nader MC, Ramirez M, Irvin GL, (2003) Comparison of intraoperative $\mathrm{iPTH}$ assay (QPTH) criteria in guiding parathyroidectomy: Which criterion is the most accurate. Surgery 134: 973-979.

42. Gauger PG, Agarwal G, England BG, Delbridge LW, Matz KA, et al. (2001) Intraoperative parathyroid hormone monitoring fails to detect double parathyroid adenomas: A 2-institution experience. Surgery 130: 1005-1010.

43. Horanyi J, Duffek L, Szlavik R, Darvas K, Lakatos P, et al. (2003) Parathyroid surgical failures with misleading falls of intraoperative parathyroid hormone levels. J Endocrinol Invest 26: 1095-1099. 
44. Yamashita H, Gao P, Noguchi S, Cantor T, Uchino S, et al. (2002) Role of cyclase activating parathyroid hormone (1-84 PTH) measurements during parathyroid surgery: Potential improvement of intraoperative pth assay. Ann Surg 236: 105-111.

45. Barczynski M, Konturek A, Hubalewska-Dydejczyk A, Cichon S, Nowak W (2009) Evaluation of Halle, Miami, Rome, and Vienna intraoperative iPTH assay criteria in guiding minimally invasive parathyroidectomy. Langenbecks Arch Surg 394: 843-849.

46. O'Neal PB, Poylin V, Mowschenson P, Parangi S, Horowitz G, et al. (2009) When initial postexcision PTH level does not fall appropriately during parathyroidectomy: What to do next. World J Surg 33: 1665-1673.

47. Yang GP, Levine S, Weigel RJ (2001) A spike in parathyroid hormone during neck exploration may cause a false-negative intraoperative assay result. Arch Surg 136: 945-949.

48. Riss P, Krall C, Scheuba C, Bieglmayer C, Niederle B (2013) Risk factors for "PTH spikes" during surgery for primary hyperparathyroidism. Langenbecks Arch Surg 398: 881-886.

49. Riss P, Kaczirek K, Heinz G, Bieglmayer C, Niederle B (2007) A “defined baseline" in PTH monitoring increases surgical success in patients with multiple gland disease. Surgery 142: 398-404.

50. Sadeghi N, Akin E, Lee JY, Roland J, Knoll S (2008) Targeted parathyroidectomy: Effectiveness and intraoperative rapid-parathormone dynamics. Laryngoscope 118: 1997-2002.

51. Wilhelm SM, Wang TS, Ruan DT, Lee JA, Asa SL, et al. (2016) The american association of endocrine surgeons guidelines for definitive management of primary hyperparathyroidism. JAMA Surg 151: 959-968.

52. Cassinello N, Ortega J, Lledo S (2009) Intraoperative real-time (99m)Tcsestamibi scintigraphy with miniature gamma camera allows minimally invasive parathyroidectomy without ioPTH determination in primary hyperparathyroidism. Langenbecks Arch Surg 394: 869-874.

53. Bergenfelz A, Lindblom P, Tibblin S, Westerdahl J (2002) Unilateral versus bilateral neck exploration for primary hyperparathyroidism: A prospective randomized controlled trial. Ann Surg 236: 543-551.

54. Sebag F, Shen W, Brunaud L, Kebebew E, Duh QY, et al. (2003) Intraoperative parathyroid hormone assay and parathyroid reoperations. Surgery 134: 1049-1055.

55. Irvin GL, Molinari AS, Figueroa C, Carneiro DM (1999) Improved success rate in reoperative parathyroidectomy with intraoperative PTH assay. Ann Surg 229: 878-879.

56. Noureldine SI, Gooi Z, Tufano RP (2015) Minimally invasive parathyroid surgery. Gland Surg 4: 410-419.

57. Gawande AA, Monchik JM, Abbruzzese TA, Iannuccilli JD, Ibrahim SI, et al. (2006) Reassessment of parathyroid hormone monitoring during parathyroidectomy for primary hyperparathyroidism after 2 preoperative localization studies. Arch Surg 141: 381-384.

58. Berber E, Parikh RT, Ballem N, Garner CN, Milas M, et al. (2008) Factors contributing to negative parathyroid localization: An analysis of 1000 patients. Surgery 144: 74-79.

59. Adkisson CD, Koonce SL, Heckman MG, Thomas CS, Harris AS, et al. (2013) Predictors of accuracy in preoperative parathyroid adenoma localization using ultrasound and Tc-99m-Sestamibi: A 4-quadrant analysis. Am J Otolaryngol 34: 508-516.

60. Sugg SL, Krzywda EA, Demeure MJ, Wilson SD (2004) Detection of multiple gland primary hyperparathyroidism in the era of minimally invasive parathyroidectomy. Surgery 136: 1303-1309.

61. Haber RS, Kim CK, Inabnet WB (2002) Ultrasonography for preoperative localization of enlarged parathyroid glands in primary hyperparathyroidism: Comparison with $(99 \mathrm{~m})$ technetium sestamibi scintigraphy. Clin Endocrinol 57: 241-249.

62. Steward DL, Danielson GP, Afman CE, Welge JA (2006) Parathyroid adenoma localization: Surgeon-performed ultrasound versus sestamibi. Laryngoscope 116: 1380-1384.

63. Solorzano CC, Carneiro-Pla DM, Irvin GL, (2006) Surgeon-performed ultrasonography as the initial and only localizing study in sporadic primary hyperparathyroidism. J Am Coll Surg 202: 18-24.
64. Zawawi F, Mlynarek AM, Cantor A, Varshney R, Black MJ, et al. (2013) Intraoperative parathyroid hormone level in parathyroidectomy: Which patients benefit from it. J Otolaryng Head Neck Surg 42: 56.

65. Anton RC, Wheeler TM (2005) Frozen section of thyroid and parathyroid specimens. Arch Pathol Lab Med 129: 1575-1584.

66. Tampi C, Chavan N, Parikh D (2014) Intraoperative parathyroid hormone assay-Cutting the Gordian knot. Indian J Endocrinol Metab 18: 210-212.

67. Harrison BJ, Triponez F (2009) Intraoperative adjuncts in surgery for primary hyperparathyroidism. Langenbecks Arch Surg 394: 799-809.

68. Chen H, Mack E, Starling JR (2005) A comprehensive evaluation of perioperative adjuncts during minimally invasive parathyroidectomy: Which is most reliable. Ann Surg 242: 375-380.

69. Greene JA (2016) Do-it-yourself medical devices-Technology and empowerment in american health care. N Engl J Med 374: 305-308.

70. Jani IV, Peter TF (2013) How point-of-care testing could drive innovation in global health. N Engl J Med 368: 2319-2324.

71. Udelsman R, Donovan PI (2004) Open minimally invasive parathyroid surgery. World J Surg 28: 1224-1226.

72. Nelson CM, Victor NS (2007) Rapid intraoperative parathyroid hormone assay in the surgical management of hyperparathyroidism. Perm J 11: 3-6.

73. Sugino K, Ito K, Nagahama M, Kitagawa W, Shibuya H, et al. (2010) Minimally invasive surgery for primary hyperparathyroidism with or without intraoperative parathyroid hormone monitoring. Endocr J 57: 953-958.

74. St John A, Price CP (2014) Existing and emerging technologies for pointof-care testing. Clin Biochem Rev 35: 155-167.

75. Richards ML, Thompson GB, Farley DR, Grant CS (2011) An optimal algorithm for intraoperative parathyroid hormone monitoring. Arch Surg 146: 280-285.

76. Morris LF, Zanocco K, Ituarte PH, Ro K, Duh QY, et al. (2010) The value of intraoperative parathyroid hormone monitoring in localized primary hyperparathyroidism: A cost analysis. Ann Surg Oncol 17: 679-685.

77. Agarwal G, Barakate MS, Robinson B, Wilkinson M, Barraclough B, et al. (2001) Intraoperative quick parathyroid hormone versus same-day parathyroid hormone testing for minimally invasive parathyroidectomy: A cost-effectiveness study. Surgery 130: 963-970.

78. Chen H, Pruhs Z, Starling JR, Mack E (2005) Intraoperative parathyroid hormone testing improves cure rates in patients undergoing minimally invasive parathyroidectomy. Surgery 138: 583-587.

79. Barczynski M, Konturek A, Cichon S, Hubalewska-Dydejczyk A, Golkowski F, et al. (2007) Intraoperative parathyroid hormone assay improves outcomes of minimally invasive parathyroidectomy mainly in patients with a presumed solitary parathyroid adenoma and missing concordance of preoperative imaging. Clin Endocrinol 66: 878-885.

80. Gurnell EM, Thomas SK, McFarlane I, Munday I, Balan KK, et al. (2004) Focused parathyroid surgery with intraoperative parathyroid hormone measurement as a day-case procedure. Br J Surg 91: 78-82.

81. Ezzat T, Philips I, Honour J, Prete F, Smart J, et al. (2013) Intraoperative parathyroid hormone measurement during parathyroidectomy is cost effective. In: 33rd BAETS annual scietific meeting, Rome.

82. Chin CD, Linder V, Sia SK (2012) Commercialization of microfluidic point-of-care diagnostic devices. Lab Chip 12: 2118-2134.

83. Joint Meeting of the German Association of Endocrine Surgeons (CAEK) and the British Association of Endocrine and Thyroid Surgeons (BAETS). Langenbecks Arch Surg 401: 1045-1091.

84. Irvin GL, Deriso GT, (1994) A new, practical intraoperative parathyroid hormone assay. Am J Surg 168: 466-468.

85. Miura D, Wada N, Arici C, Morita E, Duh QY, et al. (2002) Does intraoperative quick parathyroid hormone assay improve the results of parathyroidectomy. World J Surg 26: 926-930.

86. Perrier ND, Ituarte PH, Morita E, Hamill T, Gielow R, et al. (2002) Parathyroid surgery: Separating promise from reality. J Clin Endocrinol Metab 87: 1024-1029. 
Citation: Shawky M, Abdel-Aziz TE, Kurzawinski TR (2018) Modern Parathyroid Surgery and Intra-Operative Hormone Monitoring; Present Status, Future Concepts. J Steroids Horm Sci 9: 190. doi:10.4172/2157-7536.1000190

Page 10 of 10

87. Calo PG, Pisano G, Loi G, Medas F, Barca L, et al. (2013) Intraoperative parathyroid hormone assay during focused parathyroidectomy: The importance of 20 minutes measurement. BMC Surg 13: 36.

88. Lombardi CP, Raffaelli M, Traini E, Di Stasio E, Carrozza C, et al. (2008) Intraoperative PTH monitoring during parathyroidectomy: The need for stricter criteria to detect multiglandular disease. Langenbecks Arch Surg 393: 639-645

89. Libutti SK, Alexander HR, Bartlett DL, Sampson ML, Ruddel ME, et al. (1999) Kinetic analysis of the rapid intraoperative parathyroid hormone assay in patients during operation for hyperparathyroidism. Surgery 126: 1145-1150.

90. Gauger PG, Mullan MH, Thompson NW, Doherty GM, Matz KA, et al. (2004) An alternative analysis of intraoperative parathyroid hormone data may improve the ability to detect multiglandular disease. Arch Surg 139: 164-169.

91. Bishop B, Wang B, Parikh PP, Lew JI (2015) Intraoperative parathormone monitoring mitigates age-related variability in targeted parathyroidectomy for patients with primary hyperparathyroidism. Ann Surg Oncol 22: S655-S661.

92. Agarwal G, Sadacharan D, Ramakant P, Shukla M, Mishra Sk (2012) The impact of vitamin D status and tumor size on the intraoperative parathyroid hormone dynamics in patients with symptomatic primary hyperparathyroidism. Surg Today 42: 1183-1188.

93. Adler JT, Sippel RS, Chen H (2010) 25-hydroxyvitamin D status does not affect intraoperative parathyroid hormone dynamics in patients with primary hyperparathyroidism. Ann Surg Oncol 17: 2958-2962.

94. Sohn JA, Oltmann SC, Schneider DF, Sippel RS, Chen H, et al. (2015) Is intraoperative parathyroid hormone testing in patients with renal insufficiency undergoing parathyroidectomy for primary hyperparathyroidism accurate. Am J Surg 209: 483-487.

95. Parikh PP, Allan BJ, Lew JI (2014) Surgical treatment of patients with mildly elevated parathormone and calcium levels. World J Surg 38: 1289-1295.

96. Carneiro DM, Irvin GL (2002) New point-of-care intraoperative parathyroid hormone assay for intraoperative guidance in parathyroidectomy. World J Surg 26: 1074-1077.

97. Nilubol N, Weisbrod AB, Weinstein LS, Simonds WF, Jensen RT, et al. (2013) Utility of intraoperative parathyroid hormone monitoring in patients with multiple endocrine neoplasia type 1-associated primary hyperparathyroidism undergoing initial parathyroidectomy. World J Surg 37: 1966-1972.

98. Sharma J, Weber CJ (2009) Surgical therapy for familial hyperparathyroidism. Am Surg 75: 579-582.

99. Irvin GL, Solorzano CC, Carneiro DM (2004) Quick intraoperative parathyroid hormone assay: Surgical adjunct to allow limited parathyroidectomy, improve success rate, and predict outcome. World J Surg 28: 1287-1292.

100. Johnson LR, Doherty G, Lairmore T, Moley JF, Brunt LM, et al. (2001) Evaluation of the performance and clinical impact of a rapid intraoperative parathyroid hormone assay in conjunction with preoperative imaging and concise parathyroidectomy. Clin Chem 47: 919-925.

101. Nehs MA, Ruan DT, Gawande AA, Moore FD, Cho NL (2013) Bilateral neck exploration decreases operative time compared to minimally invasive parathyroidectomy in patients with discordant imaging. World J Surg 37: 1614-1617.

102. Chen H, Sokoll LJ, Udelsman R (1999) Outpatient minimally invasive parathyroidectomy: A combination of sestamibi-SPECT localization, cervical block anesthesia, and intraoperative parathyroid hormone assay. Surgery 126: 1016-1021.

103. Westerdahl J, Bergenfelz A, Lindblom P, Tibblin S (2007) Unilateral versus bilateral neck exploration for primary hyperparathyroidism: Five-year follow-up of a randomized controlled trial. Ann Surg 246: 976-980.

104. Velicescu C, Branisteanu D, Grigorovici A, Gatu A, Preda C, et al. (2015) Quick intraoperative PTH assay improves cure rate of minimally invasive surgery in patients with primary Hyperparathyroidism. Acta Endocrinologica 11: 457-462.

105. Kim HG, Kim WY, Woo SU, Lee JB (2015) Minimally invasive parathyroidectomy with or without intraoperative parathyroid hormone for primary hyperparathyroidism. Ann Surg Treat Res 89: 111-116.

106. Bobanga ID, McHenry CR (2017) Is intraoperative parathyroid hormone monitoring necessary for primary hyperparathyroidism with concordant preoperative imaging. Am J Surg 213: 484-488.

107. Riss P, Scheuba C, Asari R, Bieglmayer C, Niederle B (2009) Is minimally invasive parathyroidectomy without QPTH monitoring justified. Langenbecks Arch Surg 394: 875-880.

108. Smith N, Magnuson JS, Vidrine DM, Kulbersh B, Peters GE (2009) Minimally invasive parathyroidectomy: Use of intraoperative parathyroid hormone assays after 2 preoperative localization studies. Arch Otolaryngol Head Neck Surg 135: 1108-1111.

109. Carty SE, Worsey MJ, Virji MA, Brown ML, Watson CG (1997) Concise parathyroidectomy: The impact of preoperative SPECT 99m Tc sestamibi scanning and intraoperative quick parathormone assay. Surgery 122: 1114-1116.

110. Grant CS, Thompson G, Farley D, van Heerden J (2005) Primary hyperparathyroidism surgical management since the introduction of minimally invasive parathyroidectomy: Mayo Clinic experience. Arch Surg 140: 472-478.

111. Richards ML, Thompson GB, Farley DR, Grant CS (2008) Reoperative parathyroidectomy in 228 patients during the era of minimal-access surgery and intraoperative parathyroid hormone monitoring. Am J Surg 196: 937-942.

112. Shawky M, Ezzat Abdel-Aziz T, Beale T, Morley S, Bomanji J, et al. (2016) Clinical value of ultrasound, MIBI and intra-operative parathyroid hormone monitoring in patients with hyperparathyroidism. Joint Meeting of the German Association of Endocrine Surgeons (CAEK) and the British Association of Endocrine and Thyroid Surgeons (BAETS). Langenbecks Arch Surg 401: 1045-1091.

113. Nair CG, Babu MJ, Jacob P, Menon R, Mathew J (2016) Is intraoperative parathyroid hormone monitoring necessary in symptomatic primary hyperparathyroidism with concordant imaging. Indian J Endocrinol Metab 20: 512-516.

114. Chick WK, Tai DK, Shek AC, Tang PL (2017) Use of intraoperative parathyroid hormone assay in primary hyperparathyroidism: A selective approach. Surg Prac 21: 42-49. 